\title{
DEVANEIOS DE UM PROFESSOR HERÉTICO, IMPENITENTE, PERTINAZ E OBSTINADO. \\ Manifesto de um réu confesso
}

Guy Barros Barcellos

Um manifesto é como uma comunicação feita ao mundo inteiro, onde não há como pretensão nada mais que a descoberta de um meio de curar instantaneamente a sifilis política, astronômica, artística, parlamentar, agronômica e literária. Este pode ser doce, bonomioso, ele sempre tem razão, ele é forte, vigoroso e lógico. A propósito de lógica, en me considero muito simpático'. (TZARA, 1996, p. 224)

Resumo

O presente artigo trata da expressão poética e literária, entremeada por reflexões filosóficas e pedagógicas, sobre os processos de assujeitamento e as subjetivações de um professor na escola pública durante dois anos letivos de experiência como docente de Seminários Integrados e Projetos. No texto, influenciado por Bachelard, Barthes, Cioran, Corazza, Feyerabend, Montaigne, Nietzsche, Sloterdijk, Tristan Tzara, são elaboradas escrituras heréticas e trágicas. São expressos os tensionamentos sofridos pelo autor, que também foi o sujeito da pesquisa, no decurso da vivência que causou profundas modificações no seu ser/fazer docente e redefinições epistemológicas. É um texto sagrado ao devaneio, veículo da significação de elementos da memória como objeto de estudo para alargamentos poéticos e literários sobre o ensino em uma perspectiva pluralista e transgressora. Os contrastes de claro e escuro permitem dimensionar o relevo e descrever a topologia dos (des)caminhos de um professor que, entre ciência e arte, escolhe ambas. Tratase de um texto noturno, porém capaz de lançar luz sobre nós górdios da Educação através da lucidez que somente a loucura é capaz de forjar.

Palavras-chave: subjetivação docente, educação pública, devaneio epistêmico

\section{REVERIES OF A HERETIC, UNREPENTAN'T, PERTINACIOUS AND}

OBSTINATE TEACHER.

An admitted culprit's Manifesto

Abstract

This paper deals with poetic and literary expression, interwoven by philosophical and pedagogic reflections, on the processes of subjection and subjectification of a public school teacher in a 2 year experience leading the class "Integrated Seminaries and Projects". In the text, influenced by Bachelard, Barthes, Cioran, Corazza, Feyerabend, Montaigne, Nietzsche and Tristan Tzara, tragical and heretical scriptures are elaborated. This discussion also covers the tension over the author, who's the research subject as well, in the span of this experience that has deeply transformed his decency praxis; as well as memory elements asstudy objects for poetic and literary ponderings about education in a plural and transgressive perspective.

\footnotetext{
1 “Un manifeste est une communication faite au monde entier, où il n'y a comme prétention que la découverte du moyen de guérir instantanément la syphilis politique, astornomique, artistique, parlementaire, agronomique et littéraire. Il peut être doux, bonhomme, il a toujours raison, il est fort, vigoreux, et logique. A propos de logique, je me trouve três sympathique." (Tradução minha).
} 
The light and dark contrasts allow the dimensioning of the terrain and the topologic description of the path of a teacher who, between science and art, chooses both. It is a nocturnal text, though capable of casting light over the gordian knots of education through clarity that only madness could forge.

Keywords: teacher subjectification, public school, epistemic reverie

\section{SUEÑOS DESPIERTOS DE UN MAESTRO HEREJE, IMPENITENTE, TENAZ Y OBSTINADO. Manifiesto de un acusado confeso}

\section{Resumen}

Este artículo trata de la expresión poética y literaria, entreverada con reflexiones filosóficas y pedagógicas, sobre los procesos de subyugación y subjetivación de un profesor en la escuela estatal durante dos años de experiencia como docente en la asignatura Seminarios Integrados y Proyectos. En el texto, influenciado por Bachelard, Barthes, Cioran, Corazza, Feyerabend, Montaigne, Nietzsche, Sloterdijk, Tristan Tzara, se elaboran escritos heréticos y trágicos. Se expresa la tensión que sufrió el autor, que también fue objeto de la investigación, en el transcurso de la experiencia que provocó cambios profundos en su ser / hacer docente y redefiniciones epistemológicas. Es un texto sagrado para el ensueño, un vehículo para atribuir significados a los elementos de la memoria como objeto de estudio de extensiones poéticas y literarias de la enseñanza en una perspectiva pluralista y transgresora. Los contrastes de luz y oscuridad permiten dimensionar el relieve y describir la topología de los (des) caminos de un profesor que, entre ciencia y arte, elige ambos. Es un texto nocturno, pero capaz de iluminar nodos gordios de la Educación, por medio de la lucidez que solo la locura es capaz de forjar.

Palabras clave: subjectificación docente, escuela pública, ensueño epistémico

\section{EIS UM ESCRITO RODADO EM MIMEÓGRAFO}

Digitado com letras pálidas, indefesas e indefinidas. É o jorro de luz de uma auto trepanação. David Hume (1972, p. 27) afirmou que "Todas as ideias, em especial as abstratas, são naturalmente vagas e obscuras; a mente tem delas apenas um escasso domínio. E são propensas a confundir-se com outras idéias semelhantes" assim, sendo este um trabalho sobre ideias, reminiscências, reflexões e devaneios, não pretendo escapar da natureza descrita pelo filósofo. Abdico da exatidão, da clareza e do (desejo de) domínio. Dominó de entendimentos provisórios, suspendo a razão de querer, em detrimento da rasa sensação que dá letras a quem as lê. A propensão em confundir-se funde-se ao desejo.

[Homem descabelado entra em cena, ofegante, olha para a plateia, desesperado, esfrega as mãos no rosto. Olhos esbugalhados. Inspira para gritar. Perde o fôlego. Caminha de um lado a outro do palco. Corre desolado. Sai de cena.]

Hume (1972, p. 38) afirma que "Quanto à Experiência passada, pode aceitar-se que ela fornece uma informação direta e certa apenas dos objetos preciosos e do exato período de tempo, que se tornaram conhecimento seu [...]", assim sendo, buscando conhecer - afinal de contas, para que se faz um doutorado? - entendi que precisaria passar por uma experiência.

Ainda-não / Agora, a terceira e penúltima posição dos textos: aquela do aindanão. Ou seja, a do ainda-não experimentado, a do ainda-não desejado, a do aindanão pensado, a do ainda-não amado, a do ainda-não pesquisado, a do ainda-não escrito, a do ainda-não abandonado. Mas, quem sabe um dia ou uma noite... (CORAZZA, 2008, p. 65) 
Mas qual? Que experiência era esta de que precisava para considerar-me no caminho de um legítimo "dotô"? Como poderia escapar da inescapável marca livresca, teórica, masturbatória e da inócua caminhada de uma pesquisa em Educação? Menti desgraçadamente na vida. Faria o mesmo no doutorado? Pareceu-me interessante buscar uma outra forma de desonestidade... Afinal, se não tenho como livrar-me da nódoa do pecado, que não seja essa mancha a da falta de criatividade. Assim, resolvi adoecer. Resolvi buscar uma forma de profundidade que favorecesse o emergir de todas as pestilências e enfermidades. Como diz Cioran (2012, p. 39), “[...] as únicas experiências verdadeiramente autênticas são as que brotam da doença. [...] Só as pessoas que realmente sofrem são capazes de conteúdos autênticos e de uma seriedade infinita". Então, era isso! Adoeceria. Queria contaminar-me, afinal de contas, com a mais venenosa e infecta realidade.

Sob sombra de certeza, posso afirmar que, junto à decisão de "cair doente", vinha - no arraste - um frívolo sentimento de heroísmo.

Ninguém alcança logo de saída a frivolidade. É um privilégio e uma arte; é a busca do superficial por aqueles que, tendo descoberto a impossibilidade de toda certeza, adquiriram nojo dela; é a fuga para longe desses abismos naturalmente sem fundo que não podem levar a parte alguma. (CIORAN, 2011a, p. 20)

Ora, estava disposto a abdicar do paraíso. Estava disposto a descer às abissas, a queimar minhas narinas na acidulência de emanações sulfurosas da puta realidade (à época, ainda acreditava nisso). Como autômato, sem entender bem as razões, comprei minha passagem só de ida para para o inferno (e mamãe nem avisou!). Bastava de jardins flóridos, de danças no bosque e de museus reluzentes. Bastava de sorrisos e alaridos. Tudo aquilo esvaziou-se de sentido, por sentir - havia muito - o mesmo que nem sei dizer. Sentia-me saudavelmente feliz, o que é um claro sinal de falta de saúde intelectual. Que sujeito era aquele? Quem era aquele empertigado cheio de certezas, transpirando perfume francês? Coitado dele. Ele desistiu de continuar sendo o que era para tornarse o que sempre foi, e, por razões banais, sem qualquer nobreza. Pelo puro egoísmo de olhar-se no espelho e ver-se menos aquilo que não queria ser. Queria transformar meu destino numa questão subjetiva e ao mesmo tempo universal e, para isso, devia "[...] descer todos os degraus de um inferno íntimo" (CIORAN, 2012, p. 53).

$\mathrm{Na}$ tresloucada marcha rumo à desintegração, imbuí-me da atitude fundamental que, conforme Cioran (2012), se opõe à ingenuidade: a atitude heroica. Concordo bovinamente com o autor quando diz serem os dois únicos caminhos para "[...] não sucumbir à imbecilidade" (CIORAN, 2012, p. 61), uma possibilidade que me atormenta frequentemente. Restava-me o heró́smo, e "[...] a atitude heroica é o privilégio e a maldição de quem se desintegrou na vida. Ser herói [...] é desejar um triunfo radical, que só pode ser obtido por meio da morte". Eu estava disposto a matar o que de mim fosse necessário para que triunfasse.

[Entra uma ratazana. Olha, de soslaio, para a plateia baixa. Aproxima-se, desafiadora. Pega um farelo. Examina. Abandona o farelo e corre, como se fugisse de algo, que jamais vem. Sai de cena].

Enquanto os ratos não falarem, meus amigos, posso ficar tranquilo. Tudo está bem. Apesar disso, tudo o que em mim brota é minha bancarrota. Minhas criações são mais do que atos, são putrefações... "Cada vez que temos uma ideia, algo apodrece em nós" (CIORAN, 2011b, p. 31). Céus! Eu e o Felipe (um amigo poeta) num restaurante. Indaga-nos — para meu desconcerto - o garçom: Vocês são comediantes? Felipe responde rapidamente: Não, somos tragedos! Consertoume. Ali descobri minha vocação. Fui batizado. Minhas putrefatas ideias são tragédias encomendadas pelo caos que me habita. E, finalmente!, meus amigos, finalmente consegui iniciar o caminho para o abismo tão sonhado. Quero, como Cioran (2012, p. 70), “[...] arrebentar numa 
explosão radical com tudo o que há dentro de mim, com toda a energia e todos os conteúdos, escorrer, decompor-me e que, numa expressão direta, minha própria destruição fosse minha obra, minha criação, minha inspiração". Como é morbidamente maravilhoso pensar que já engatinhava em direção ao meu desejado abismo sem saber! Que maravilha ainda maior — talvez arrebatadora - pensar para quais abismos caminho agora, sem ter a menor ideia... E, afinal, o que quero com isso tudo?

Nada é demais. É menos. Quero meu lirismo. Quero encantar as ninfas açougueiras que irão me despedaçar e aspergir-me nos cantos da Terra. Quero aprender a tocar esta lira que nasce com cada um de nós e fica, em tantos, e para a sorte deles, intemerata. Quero, neste lirismo, monumentalizar minha demência. Quero ver o que vi de mim e contar. Quero contar o que vi de mim e ver os rastros de gosma nesta lenta viagem nas entranhas do pouco que posso conhecer do mundo, que é o pouco de mim que posso conhecer. Dentro do que permite o limite das minhas capacidades, até porque "Já é satisfação bastante podermos chegar até aqui, sem nos lamentarmos da estreiteza das nossas faculdades, porque não nos levarão mais longe” (HUME, 1972, p. 47). O longe que for não será perto o bastante para descobrir que nada de muito interessante há para ser descoberto fora daquilo que chamamos de interior. Eu precisava aprofundar, afundar no que não sabia - e ainda não sei — bem o quê. Demorei a descobrir que "É fácil ser 'profundo'; basta deixar-se invadir por suas próprias taras" (CIORAN, 2011b, p. 15). O problema era (querer) conhecê-las... Precisava de um curso de mergulho. Mas fazê-lo diminuiria as chances de afogarme. Uma (in)consciência dominou-me, como o parasita que faz a formiga subir à ponta da folha para ser devorada pela vaca, e subi, oferecido, ao repasto do grande ruminante sistema... Menos saudável do que estivera, começaram os passos ao almejado báratro. Ao mergulho. Iniciou-se a natação catadrômica do Polvo. E "Tudo o que é profundo neste mundo só pode brotar a partir da doença. $\mathrm{O}$ que não brota da doença não tem mais do que valor estético e formal. Estar doente significa viver $[\ldots]$ nos cumes. Os cumes, porém, não indicam necessariamente altura, mas penhasco, profundeza" (CIORAN, 2012, p. 75). Touche! Eis que achava (que achava) o caminho para minha danação. Uma gargalhada fez espalancar as bordas do Orco. Desfraldava-se um Inferno!

[Luz verde no palco. Corifeu de ratazanas (imensas): “Coitado dele! Rá-rá-rá! Coitado! Sentimos tanta pena que deveríamos ser galinhas, não ratazanas. Como é triste ver um mendigo andrajoso escondendo suas fedentinas com perfumes emprestados! Coitado dele! Rá-rá-rá! Coitado!" Apagam-se as luzes].

Danei-me. Apesar de não ter mais remota ideia sobre o que falo, dado o avançado estágio de composição das ideias, cavo algo que esteve dentro de recônditos cantos ainda não tocados pela luz. Temo, e com boas razões, a luz. Solífugo, lucífago e ombrófilo, escondo-me das luzes da ciência e seu aborto: o método. As ideias são fotossensíveis e decompõem-se sob a claridade do rigor. Gárgula craquelada pela insolação impiedosa que fustiga a pedra, alço voo na noite do solstício da vida acadêmica buscando esconderijo no qual possa desabrochar as ideias-raflésias e atrair moscardos que mergulhem no acídico néctar digestivo do sentimento descomprometido de qualquer racionalização metódica, consistente, embasada, válida e pré moldada. Salve-me, Deus, Jesus e o Diabo de qualquer modelagem. Norma só a ópera, e aquelas da língua portuguesa, para que a náusea de ler o que outro escreveu seja menos intensa. Quem estimulou minha descida traiume, querendo, como relato da viagem, uma carta de Pero Vaz de Caminha. Nada de fuligem. Sem gemidos. Somente belos dias. Tudo está bem. Tudo está no seu devido lugar.

[Luz tênue, esverdeada, sobre o palco. Som seco, batidas ritmadas. Surge um homem. Corcunda. Caminha lentamente, como se se arrastasse. Arfa, quase asmático. Caminha até o centro do palco. Pára. Suspira longamente. Vira a face à plateia. Rosto contraído, enrugado. Olhar 
assassino. Geme. Retoma a caminhada, balbuciando pragas (ininteligíveis). Tosse. Escarra. Sentase ao fundo do palco. Começa a comer uma maçã. Mastiga alto. Estracinha a maçã como se fosse uma carniça. Pára. Olha a plateia, desconfiado. Gesticula com desprezo, dando a entender que não quer chamar atenção. Respira com dificuldade, enfisematoso. Pigarreia. Joga a maçã mordida ao chão. Levanta-se com imensa dificuldade. Amaldiçoa grunhindo. Arrastando-se, sai de cena. Apaga-se a luz].

Aqui, senhores, aqui pretendo tocar a lira que usei nas baixezas. No ceco do mundo aprendi a tocar som que não fez Cérbero dormir, pelo contrário. Queria/quero exercer o lirismo da insônia. Acordes dissonantes para despertar Fúrias famintas. Nesta pulsão camicase, viajo por nebulosas interiores, rumo ao Nada. O que vi(vi) no Inferno? Não ouso comediar. Afinal de contas, sou tragedo. A subtileza de toda aquela violência é inexplicável, é prisão. Pois bem, eis que surge um irado nimbo. Um além-cúmulo. Ruge! Falemos sobre do que se tratará (Taratá!) neste texto. Sou ateu de tudo. Nem sempre o fui. Já cri em Papai Noel. Cri em Deus. Cri na Ciência. "Mas a ciência não é sacrossanta. O mero fato de que existe, é admirada e tem resultados não é suficiente para fazer dela uma medida de excelência" (FEYERABEND, 2011, p. 273).

Resta-me nada. Nesta chafurdação ateísta, vejo-me desprovido da mais remota possibilidade de recorrer a qualquer reza que seja. Talvez minha tábua de salvação seja a literatura. Se é que alguém (se) salva de alguma coisa. Padeço de letras. Sinto-as querendo sair pelos dedos, pelos poros. Hemoptise de palavras. Hemorragia de parágrafos. Sobre a sutileza, sobre o não explicável, quero ater-me. Para Roland Barthes (1989, p. 19) "A ciência é grosseira, a vida é sutil, e é para corrigir essa distância que a literatura nos importa". Não encontro meio (de cultura) no qual possam vicejar minhas palavras. O corte cirúrgico do formalismo acadêmico - bisturi que sempre segurei trêmulo - é corrigido pela capilarização incontrolável das aguadas que se encontram e for(m)am novas cores, indecorosas. Resta, portanto, trapacear com a língua. É uma trapaça salutar, uma esquiva, um magnífico logro que permite fugir do poder, numa esplendorosa revolução chamada literatura (BARTHES, 1989). Entenda-se por "[...] literatura não um corpo ou uma sequência de obras, nem mesmo um setor de comércio ou de ensino, mas o grafo complexo das pegadas de uma prática: a prática de escrever" (BARTHES, 1989, p. 17). Escrevo, portanto, pois é o que me resta, me cabe, me inspira, me salva, me dá prazer. Não tenho competência de negociar com o desprazer. Tudo isto é um libelo epicurista de um porco atolado na lama de sua teimosia. As emanações nauseabundas são um repelente à incansável polícia do pensamento. Ademais, nenhum freio se pode colocar aos raciocínios dos pesquisadores, a não ser que estes possam constituir ameaça à humanidade (HUME, 1972).

Sinto uma crônica indigestão, no sentido titânico e tantálico. Engoli os filhos dos outros, não me deixaram gestar meus próprios. Não há rifampicina que cure esta tísica intelectiva. Empanturrado de referenciais, sinto uma insatisfação de quem bebeu água salgada buscando matar a sede. Cato citações no recato das bibliotecas e canto, a plenos pulmões, nada do que a musa antiga canta. Caem todos os valores. Nada quero que valha na velha escola. Não poss(u)o mais. Não quero mais repetir. Estas são mãos de quem não aceita mais repetir. Mãos que festejam. Mãos de arte(com)tesão. Fosse capaz, escreveria em um novo idioma e um novo alfabeto.

Vontade de festejar o pensamento (apesar do velório que me aguarda). Vontade de carnavalizar as ideias, descarnadas pelo rigor. Vontade de libertar meu espírito científico (aguardem Gaston!). Vontade de liberar as massas do maçante Nada que paira, inexorável.

[Luz pálida sobre o palco. Aparece um cepo no centro do proscênio. Achas de lenha cercam o cepo. Apaga-se a luz].

Este é um trabalho sobre subjetivações e assujeitamentos. É um estudo de formações com arredores irregulares, gauches, acid(dentad)os e indefinidos. Não se trata de um lugar no qual se 
chegou, mas de um lento rastejar num mar de Aral criativo. É caminhada (in)cansável, cantabile, desvairada em meio ao total caos da miopia incorrigível e inexorável e que não quer nada além de dizer o que se enxerga das escotilhas de um Kursk indirigível e indigerível por qualquer estômago aziago. Atrida que sou, esvazio cada átrio e ventrículo com válvulas rompidas nos percalços de uma peregrinação sem Deus, sem fé, mas repleta de consciência do que mostrou Cioran, "[...] que descobriu a maneira mais saudável de ser incurável” (SLOTERDIJK, 2013, p. 82). Não há cura para um curador de coleções voláteis, versáteis e diversas na perversidade de um(a) corte que, sem dó, mi, nem $\pi$ e idade, mas com Sol. Arado de pensamentos que vincam um solo de terreno salitroso. Nesta migração sem sextante, sem bússola nem mapa, buscou-se apoio somente dos haustos do pensamento ardido, pois "[...] tanto nos apoiamos nos outros que acabamos por perder as forças" (MONTAIGNE, 1972, p. 75). Não tenho como falar de/ por/ sobre/ em outros. Só posso referir-me a/ por/ sobre/ de/ em mim. Como poderia dizer por outro? Como poderia dizer (de mim) o que (pen)sei usando a pena de outros? Resta cantar minha própria música, até porque "[...] ninguém pode ouvir nas coisas, inclusive nos livros, mais do que já sabe. Para aquilo a que não se tem acesso por vivência, não se tem ouvido" (NIETZSCHE, 1974, p. 383).

Erisícton empanturrado, anulado pelo furor. Que fome de si que causa em alguém tamanho solipsismo. Somente o cinismo antropofágico de um ensimesmamento lacrado na teimosia de um bivalve. Hermetismo esquizóide e categórico no qual se pensa saber sozinho e querer em-sina(rra)r-se a ventura de tentar tornar-se, sem saber, o que sempre foi. Hão de ver um monumento demente que nada mais visa a pedir licença para que se diga. Exercer "[...] o direito de dizer tudo, ainda que a título de ficção e de experimentação do saber, e o direito de dizê-lo publicamente, de publicá-lo" (DERRIDA, 2003, p. 18). Rejeito, portanto, um objetivo fixo em vista, pois não sou (mais) capaz de exercícios metódicos. Como Cioran, pratico a rejeição a todas as vias dirigidas a um objetivo de prática e, neste espírito, busco a "[...] desconstrução das noções de base e, de outra parte, a concretização entre noções descoloridas" (BACHELARD, 1968, p. 27), colorizadas por minha total inópia para o objetivo e o desejo irrefreável de usar o lirismo para transcender do empirismo ao onirismo. Mesmo que se fique pousado no idiotismo.

Quero ter coragem de me servir de meu próprio entendimento, e eis um projeto nebuloso, talv-espontâneo, autobiográfico dada adoecido, uma quasi-exumação, pois "[...] não se pode ser um autobiógrafo sem ser um autopatógrafo, o que significa publicar seu prontuário médico. Ser honesto significa dizer o que lhe falta" (SLOTERDIJK, 2013, p. 74). Significa dizer, portanto. E, fazendo-o, a cada espaço o que falta se mostra, enudece e emudece a patologia de um Quasímodo que sonha em ser Rigoletto e gritar: Cortiggiani, vil razza dannata! Opero com poucos elementos, transfigurados por um desejo empedoclesiano de pular na garganta do Etna. A deformação de um professor que se desconstruiu tentando justa/ampla-mente ver que não estranha, dado o modo clássico pelo qual se aprende, que "[...] nem alunos nem mestres se tornam mais capazes embora se façam mais doutos" (MONTAIGNE, 1972, p. 75), ter perdido qualquer pretensão de algo conseguir com este algo(z). Creio ter aceito o convite de Barthes, visto não ser sua "Aula" (1989) "[...] uma fala magistral mas uma escritura, nunca é uma ameaça de opressão, mas um convite ao jogo" (BARTHES, 1989, p. 57). Por isso, faço desta escritura uma festa, ébria como o barco, como a rolha flutuante de Rimbaud. Uma festa de transubstanciação do saber em sabor. Buscando a "Sapientia: nenhum poder, um pouco de saber, um pouco de sabedoria, e o máximo de sabor possível” (BARTHES, 1989, p. 49).

[Luz azul no palco. Cepo e lenha continuam ali. Menino triste entra em cena. Tremebundo. Olhos marejados. Cabeça baixa. Caminha lentamente, sem vontade, até a beira do palco. Agachase e pega, no chão, um livro de capa de couro verde-escuro, com um grande "N" dourado na capa. 
Abre-o. Lê, por cinco longos minutos. Sorri. Fecha os olhos, respira fundo e dá uma imensa gargalhada. Apaga-se a luz].

Queria ser mais herói do que sábio. Queria salvar alguém e tornei-me, vejam a ironia, um apologeta do desespero. O que lerão, nada tem de fato. O que de facto tinha, já virou ficto. A (in)suficiência das palavras, larvas que me destrincham, fazem necessária a electrocução da intelecção. Quero (es)tudar, o tudo e o todo, atoleimado pela negação do completo pelo complexo (BACHELARD, 1968), pelo amplexo ao incompleto e desforme. Busquei examinar todo o possível. O possível e o real. Quis pensar em uma coisa que talvez poderia ser por meio de um compensar como um sonho, um entendimento onírico. Quis passar do pensar empírico ao pensar onírico utilizando a filosofia do "por que não?" (BACHELARD, 1968). Elabora-se um conhecimento observando as experiências, mas, ao mesmo tempo, ao escrever e oralizar. E este devir professor-aluno deve-se ao facto-ficto de que professor pode ser qualquer um que pesquisa, pois "[...] há uma idade em que se ensina o que se sabe; mas vem em seguida outra, em que se ensina o que não se sabe: isso se chama pesquisar" (BARTHES, 1989, p. 49). Este não-saber não é dissabor, é pestilência da angústia — eis este ensaio teórico para carpir o bom-senso — de não saber quem sou, somente quem estou, e não ser possível — sequer remotamente — o que os outros pensam do que sou-estou.

[...] vouloir dire / estamos saturados de certezas sem suspeita / extenuados com verdades não postas em drama / ninguém tem direito de acabar com qualquer enigma / nem de parar de nos assustar / ninguém tem direito de pôr em ordem o devastado o / irreconhecível / o repugnante o turbulento os colapsos as estações clandestinas / as figuras moribundas as artistagens marginais deletérias / os heróis como sombras de si mesmos / só queremos penas / capitais [...] (CORAZZA, 2008, p. 24)

Além disso "Nascemos para existir, não para conhecer; para ser, não para afirmar-nos. O saber, tendo irritado e estimulado nosso apetite de poder, nos conduzirá inexoravelmente a nossa perda" (CIORAN, 2011c, p. 51).

Apelo à poesia por esta impossibilidade de falar sobre/para os outros. Só posso falar deste que vos fala e, como não entenderão o mesmo que entendi (agora, neste momento), recorro à poesia para que entendam o que quiserem. Escudo-me, também, em Nietzsche (1974), que disse ser ele uma coisa, outra seus escritos, que abdicou da pretensão do entendimento alheio do que escreveu, por fazê-lo tão displicentemente quanto convinha.

A poesia que para nada serve, que, de tão inútil, diz sequer o que quero que pensem que disse. Quero, sim, que outros estudem o que lhes pareça útil, pois eu irei fazer o que para coisa alguma serve. Gero um beijo futuro nas margens separadas pelo corte. A serpente da corte. A co(o)rte de vultúrias-cupim estracinhando o rebotalho de um texto sem-fundos. Uma negação da verdade e do completo, porque isso é, justamente, o desejo de verdade do espírito científico (BACHELARD, 1968). É fuga do obscurantismo da luz, escapar do fetichismo da razão e do fanatismo do universal e aceno ao entendimento de que "[...] o real é um caso particular do possível. Essa perspectiva é, sem dúvida, adequada a marcar um alargamento do espírito científico" (BACHELARD, 1968, p. 48). Permissividade do devaneio no vago projeto de feira de (insufi)ciência(s) — das palavras, na feira de produtos orgânicos do pensamento.

Esta preparação teórica (in)dispensável é/está um acinte ao artista que nada quer, pois “[...] políticos, reformadores e todos os que reivindicam um pretexto coletivo são trapaceiros. Só a mentira do artista não é total, pois só inventa a si mesmo" (CIORAN, 2011a, p. 31). 
É um artesanato de esvurmar purulências dos processos interiores de coabitações para auto-fazer-se sujeito que é(-stá) contra os estamentos que negam a multiplicidade de ser-se/estarse. "Há coisa mais vil do que dizer sim ao mundo?" (CIORAN, 2011a, p. 85). Fazer-se(r) docente (des)legitimado, questionando a essência de si, numa exploração ontológica que não se visualiza fora do barbarismo da poesia, do lirismo que é visigótico, (h)único e incivilizado, derrama sangue insincero e chama(s) a-qu(é)m. Além da verdade nova, que nasce apesar da evidência, da experiência nova que nasce apesar da experiência imediata (BACHELARD, 1968) e premeditada pela esperança de quem tem.

Neste báratro em que se mergulha, a hipótese/hipértese é tão real quanto a experiência. Hipótese é síntese e hipértese é barbarismo abastado pela presunção de um espírito aquinhoado por vontade. Nosso espírito é um pedaço da matéria, a razão, um produto do espírito que utilizamos para explicar a realidade (BACHELARD, 1968), ou aquilo a que damos o certificado de realidade. Uma realidade cujas verdades são relativas, estudadas por domínios limitados, porque todo pensamento formal é uma simplificação psicológica inatingida, um tipo de pensamento limite jamais atingido (BACHELARD, 1968) e causador de minhas mais espinhosas perguntas, pois têm resposta. Pior do que não ter respostas é tê-las e nada poder fazer com elas, ter uma tese inflamatória, inflamável e chamar bombeiros que apagam fogo com livros.

[Luz verde no palco. Corifeu de ratazanas (imensas): "Pensa ser ele polvo, dantes nunca visto! Já visitou o inferno que quer que acreditem! Coitado dele! Rá-rá-rá! Quanta presunção em um só corpo. Carne putrefata postergada às calendas. Tolo! Acha que cantar espanta algo, alhos e bugalhos. Coitado dele! Rá-rá-rá! Diz mentiras para soarem verdades suarentas. Ai! Ai! Ai! O fedor que exala da verdade castrada querendo decolar. Quanta pena! Quanto piche! Mandem servir acepipes na ratoeira". Apagam-se as luzes.]

É preciso saber, mas "[...] cumpre indagar quem sabe melhor e não quem sabe mais" (MONTAIGNE, 1972, p. 75), também resta saber o que é saber melhor. Talvez seja saber menos, criar mais, mas "O que sabemos nós próprios? Que pensamos? Que fazemos? Um papagaio poderia substituir-nos" (MONTAIGNE, 1972, p. 75). Não! Papagaios vivem demais, e vivem porque vida é repetição. Quem cria é demiurgo, e estes jamais morrem. Sinto-me tomado por um furor (incen)diário, frenesi ígnico das origens do Cosmos. Empédocles mergulhador, voando em direção ao Nada. Queimar o que houver em mim de antigo e ir até um pretérito perfeito no qual não se busca senão o devaneio. O Universo fez fogo para nascer. A fúria do mesmo fogo devorou a Biblioteca de Alexandria. Nero de mim mesmo, aniquilo qualquer sombra de passado. Passado a limpo, conspurco as vestes e monto, leproso, despedaçado para uma guerra já perdida por uma Jerusalém-miragem. Transfigurado em Saladino, sorvo gelo e explodo relicários que não deixam pensar para a frente, seja onde for este lugar. Mais medo tem quem me acusa da sentença em executá-la do que eu em ouvi-la e sentir a lambida cálida da labareda que alça aos infernos do pensar.

Ilhado neste tubo-de-ensaio, transbordo-me a buscar quem também esteja nesta sintonia. Um tudo de ensaios que jamais encenam, que ululam ao brilho de uma Casta Diva conspurcada pelas nódoas do (pens)ar de uma alcateia que vaga, errante. Ouço, ao longe, sons desses quens pensantes, inacessíveis aos insulanos deste feudo. Apesar de estar na urbe eterna, não seguirei prescrições. Sou cartaginês disfarçado no Láscio. E lá, onde não (des)graçam alunos (des)ajustados, vi que se trata de matérias e da escrita (COSTA, 2007), tratando do que se encontra nas coisas. Tal como Campos (2013), este texto busca compor espiritografias em meio à vida mutante, usando a educação como um campo exploratório a dar vazão aos fluxos de pensamento promanados da fervura de caldeiras de um averno terreal. Os vapores que hidratam as ideais deste texto, gesticulam con-tent-áculos que emp(r)enham a mente de tinta transparente, capaz de manchar todas alvas 
vestes de um biólogo em apoptose epistêmica metastática. Um biólogo pedreiro, que faz da pesquisa um canteiro de experimentações (CAMPOS, 2013) e desvertebra-se para inveterar-se na literatura que nada resolve, graças a Deus. Uma tentativa de pensar todas as possibilidades experimentais (BACHELARD, 1968).

Dissolver e resolver, jamais. Quer-se, aqui, com todo desejo que há num ser, a abjurada concentração de um gauche quasímodo estancado pelos trombos do rigor e que, com estrondos, esvair-se-á em hemofilia de letras. "Todos os proscritos da vida provam que foram insuficientemente sórdidos...” (CIORAN, 2011a, p. 85).

Eis, camaradas, uma pró-tese pré-Cambriana, um coacervado de palavras polimerizadas pela afinidade molecular de ideias fada(da)s a serem extintas pela imensa e incoercível necessidade de caçar a imitação. Ora, por que deveria ela ser algoz de alguém incapaz de tentar ser o que ela tanto cuida para que sejam obedecendo seus livros sagrados? Feil (2009) diz ser necessário, para transgredir, insistir com as formas que nos aborrecem, na esperança que se desmontem. Mas sou gente de agorança. Meu negócio é fazer: "[...] a esperança é uma virtude de escravos" (CIORAN, 2011a, p. 187).

Eis a potência camuflativa de um molusco dacticéfalo inédito. Observem o jorro do vulcão tintureiro que de suas molengas entranhas expele a tinta que tinge o palor da folha com suas inquieta-ações, geradas por um corpo que afirma a potência do infinito de uma vida finita e a impossibilidade de permanência (SANCHOTENE, 2013), onde quer que esteja, porque, raios!, tudo que está parado se mexe como enxame, por dentro e por fora. Limites (e) impostos são alvo de minha a/trans/di/regressão e, conforme Sanchotene (2013), esta impossibilidade de permanência trata-se justamente da tentativa de negar esses limites. A permanência de uma forma definitiva é impossibilitada por aquilo que do sujeito é provisório — ou seja: tudo — e, sendo assim, um inventar vida (SANCHOTENE, 2013) é, possivelmente, o que penso ser o que desejo com esta Fuga de Bach. Cellos executam melodia contrapontista repleta de contradições, aditas ao cais de onde partiram naus jamais retornadas. Lido deserto, temor de um vento que não venha ou de borrasca que chegue de súbito e leve as enxárcias e o velame. Fico eu num barco a remo, e o mar transfigura-se em rio. Toma-me da mão o remo um alguém sombrio. Cobra uma moeda e leva ao profundo ceco do mundo.

[Luz verde no palco. Corifeu de ratazanas (imensas): "Estamos cansadas. Cansadas com letras salpicadas no vazio. Estonteia-nos a cavidade deste azedo oceano de saberes estéreis. Meninas! Vede, é um polvo nos infernos. Um polvo imolado em campo de gineceus lacrados, de androceus eunucos. Quanta tinta evaporada. Quantos poros retintos! Quantos polvos calados. Esculacho desta vida que não aprende coisa que não seja açúcar". Apagam-se as luzes].

$\mathrm{Le}(\mathrm{n}) \mathrm{do}(\mathrm{o})$ engano de encontrar no inferno o que buscava. Orlando e Orfeu sabiam o que desejavam, eu não. Quero o passeio, a caminhada, o durante. Dantes nunca navegados, rios de morte escorrem em salmoura que conserva os horrores da atroz alvorada jamais vinda, no báratro profundo, onde tudo é exalação pútrida, vi que é possível matar o morto. Na ravina aberta por onde caí, rachadura de territórios que me aprisionavam na superfície, sujei(tei)-me do que precisava para que a escrita torne-se expressão da mais absoluta loucura, do lirismo, do heroismo e de tudo mais almejado por alguém que não quer sê-lo quando crescer, mas que deseja ser anão, neotênico, tectônico e titânico, ser o que jamais foram, por mais que não se saiba de alguém ter antes conseguido. A escrita serve-me, pois é lugar de intensificação da imaginação, uma linha de fuga que nos leva a encontrar intensidades perversas e anômalas (FARINA, 2009). É a pedra fundamental do colabamento entrópico de energia represada capaz de formar Universos nos quais a grave idade só é capaz de criar nebulosas, nas quais as estrelas são buracos-negros das entrelinhas e onde a treliça de ideias assemelha-se à mais efêmera espuma do mar. Espuma gentil que não apaga as 
pegadas de quem aqui estiveram antes caminhando. Deucalião de letras, ainda aguarda raios que dêem sopro ao rebotalho. Seus andrajos tecidos com a mais fina linha, do pensamento mais cortante e patuás para os quebrantes da vetusta e imorredoura senhora, Prosérpina a quem suplico: este não é um método de explicação, mas um meio de produção (FEIL, 2009), de criação, e jamais se pode negligenciar uma possibilidade que paira sobre um objeto da criação (BACHELARD, 1968). Ademais, pressão alguma há de transformar meus carvões em diamantes, afinal, nesta gélida lura, não hão de aquecer-me pedras duras.

O que já marchou até aqui não permite ré, volta a lugar já devastado. Vejo caos, uivo a um céu sem estrelas e no qual brilham entrelinhas que sibilam como orden(h)ar ideias e talhar textos sem (p)rumo e des-re(s)-peitar/petir a estrada asfaltada, de dentro de um estuário surge a mão de Viviane: presenteia-me com uma Excalibur-facão para abrir picada e desbravar, em bravatas e macaquices, a selva opaca de um pensamento exploratório acrobata, de uma criação emiliana, de joelhos esfolados e pés enlameados.

[...] textos náufragos / scrilettori na jangada de medusa / com a energia do desespero se autodestroem / exercícios homicidas arruaças rixas motins combates furiosos / orgias de carne caos belicoso[...] (CORAZZA, 2008, p. 24)

Quis, no inferno, e quero, aqui, no purgatório, afrontar as certezas e as verdades sobre aluno, professor e escola, para ser capaz de criar (NODARI, 2013). Assim, pode-se considerar este texto como um esforço poético, um esforço criador, realizador que, por súbitas inflexões reveladoras, fazem as sílabas formar palavras, verdadeiras palavras, que falam à razão e que encontram, na realidade, uma coisa a evocar (BACHELARD, 1968). E que coisa é essa?

Pa-lavrar e alagar o pensamento construído em experiências. Larval estado, de emergência. Emergem cadáveres rejeitados pelas sapróbias de minha memória, fazem-me pensar em relação ao que faço e ao que me constitui.

Des(cons)truo-me pela necessidade de negar a estrutura, pela estatura que desejo ter, pela potência do criar que se movimenta no engenho de dentro. Questão ontológica aflige-me e faz girar a roda da Fortuna Imperatrix Mundi e ver que, como a lua, seu estado variável faz do existir caleidoscópio, cacoscópio/ giroscópio — in girum imus nocte et consumimur igni — do que vi(vi)-senti e calo-me expressando em letras e águas, de lágrimas amargas e autênticas, deste pedinte que pede e que puxa células e átomos, moléculas e átimos na fuga desesperada para salvar o que o Nada pode destruir, numa esgrima de pincel. Hão de encontrar, por este ácido rélico, o que fez tateando num baile de relevos lisos raspados pela rádula áspera da les-mínima que seca a baba e gosta de gosmar sem gozo nem regozijo. Inexorável linha que não diz respeito até que o polvo jorre tinta pálida que fecunda o presente-papel e o devir Titã-bactéria. "Nem pacto com a vida, nem pacto com a morte: havendo desaprendido a ser, consinto em apagar-me. O Devir, que crime enorme!" (CIORAN, 2011a, p. 158).

Acompanhará o mergulho no talude da insanidade um dicionário ilustrado interior feito pela não-ensaiada cegueira de um noctífago lettreferits. Ferido de morte pelos tipos, traça o papel que carcome banhando em lágrimas capazes de hidratar a mais empedernida xerófita.

[Luz pálida no palco. Mulher macérrima entra em cena. Fumando. Senta-se. Cepo e achas de lenha atrás. Termina de fumar. Olha por uma janela que não está ali. Põe para fora o braço. Gesticula ordenando algo, como se mandasse alguém sair de onde está, mas querendo que nunca saia dali. (Um gesto paradoxal). Rosna. Escreve uma receita em um pequeno caderno. Amaldiçoa, balbuciando. Escreve num quadro negro, que também não está ali. Mastiga o giz. Engasga-se. Apaga-se a luz]. 
Sangrando de regras singro um mar em tubo de ensaio, (ar)rimo de um aristocrata que sonhou ser maior seu céu do que os romanos. Teimosia em sentir que não se faz sentido ao tentá(cu)-lo em (espa)ventosas segurantes das mais remotas memórias putrefando sob areais de ampulhetas coladas na mesa de Júpiter. Acendem aos céus num campo de flores as moléculas leves de um professor que ousou ensinar a saber sonhando. Eu quero ser maldito! Deixem-me! "Que seja maldita para sempre a estrela sob a qual nasci, que nenhum céu queira protegê-la, que se disperse no espaço como uma poeira sem honra! E o instante traidor que me precipitou entre as criaturas, seja para sempre riscado das listas do tempo!” (CIORAN, 2011a, p. 222).

Texto saindo do engenho de dentro e eu saindo do eixo. Eixo de rotação, de translação tresloucada. Lá, a ação é fora da órbita dos olhos que viram Júpiter. Deus, suicida, mata-se a cada instante para renascer em ondas, vagalhões elétricos de cada grão de pó. Grave idade gravada na pedra forjada no coração de cada estrela que faz Júpiter pensar-se Lua. Judith abraça o Universo neste verso sem rima, nem remo, à deriva no pedregulho ciano, cianureto da Via Láctea intoxica cada fibra de rebeldia pura. Giordano Bruno descortina e queima os dedos no tecido ocultando o proibido saber-ser.

[Luz fortíssima sobre o palco. Mulher nariguda (apesar de não ser culpa sua). Fumando, também. Sorri. Serve café em uma xícara. Bebe. Cepo e achas de lenha estão ali, ainda, mas nunca estiveram tão ausentes. O homem assustado passa gritando, ela não se abala. A mulher magra passa fumando, ela não vê. $\mathrm{O}$ corifeu de ratazanas entra, carpindo um defunto num féretro: o corcunda enfisematoso. Ela ignora. Homem assustado, agora com olhar lascivo, entra grunhindo. Abraça-a por trás, esfrega-se lascivamente. Ela ri. O homem vai embora, não volta. O menino triste entra em cena. As ratazanas choram ainda mais alto. Joga a baga do cigarro no chão. Serve-lhe café. Ela abraça o menino com todo amor que há no mundo. A mulher magra, suja de giz, pega a baga do cigarro e come. Engasga-se. Um homem de vestes negras, com a boca tapada por uma corda de sisal é amarrado ao cepo pelas ratazanas, que já não mais choram o defunto, que desaparecera. A mulher nariguda pega o livro com um " $N$ " na capa e começa a ler, sentada ao chão, para o menino triste. Eles sorriem. A mulher macérrima vomita a baga do cigarro sobre as achas de lenha. Uma labareda sobe. As chamas começam a lamber as vestes do homem, que tenta gritar, mas não consegue. As ratazanas fogem, horrorizadas. As achas de lenha eram livros. A luz intensa apagase. Somente as chamas aparecem. Fecham-se as cortinas].

\section{REFERÊNCIAS}

BACHELARD, Gaston. Le nouvel esprit scientifique. Paris: Les Presses Universitaires de France, 10e édition, 1968.

BARTHES, Roland. Aula. Trad. Leyla Perrone-Moisés. São Paulo: Cultrix, 1989.

COSTA, C. B. Materiais de escrita. Dissertação de Mestrado. 2007. 167p. Dissertação (Mestrado em Educação) - Faculdade de Educação, Universidade Federal do Rio Grande do Sul, Porto Alegre. 2007.

CAMPOS, Maria Idalina Krause de. Alfabeto espiritográfico: escrileituras em educação. 2013. 101p. Tese (Doutorado em Educação) - Faculdade de Educação, Universidade Federal do Rio Grande do Sul, Porto Alegre. 2013.

CIORAN, Emil. Breviário de decomposição. Rio de Janeiro: Rocco, 2011a.

CIORAN, Emil. Nos cumes do desespero. São Paulo: Hedra, 2012.

CIORAN, Emil. Silogismos da amargura. Rio de Janeiro: Rocco, 2011b. 
CIORAN, Emil. História e utopia. Rio de Janeiro: Rocco, 2011c.

CORAZZA, Sandra Mara. Os cantos de Fouror: escrileitura em filosofia-educação. Porto Alegre: Sulina, 2008.

DERRIDA, Jacques. A universidade sem condição. São Paulo: Estação Liberdade, 2003.

FARINA, J. T. Deseratação. 2009. 92p. Dissertação (Mestrado em Educação) - Faculdade de Educação, Universidade Federal do Rio Grande do Sul, Porto Alegre. 2009.

FEIL, Gabriel Sausen. Procedimento erótico na formação. 2009. 247p. Tese (Doutorado em Educação) - Faculdade de Educação, Universidade Federal do Rio Grande do Sul, Porto Alegre. 2009.

FEYERABEND, Paul. Contra o método. São Paulo: Ed. Unesp, 2011.

HUME, David. Investigação sobre o entendimento humano. Lisboa: Editora Setenta, 1985.

MONTAIGNE, Michel de (1972/1976). Ensaios. São Paulo: Abril Cultural.

NIETZSCHE, Friedrich. Obras incompletas. São Paulo: Abril Cultural, 1974.

SANCHOTENE, Virgínia Crivellaro. A potência da evanescência: diferenças e impossibilidades. 2013. 101p. Dissertação (Mestrado em Educação) - Faculdade de Educação, Universidade Federal do Rio Grande do Sul, Porto Alegre. 2013.

SLOTERDIJK, Peter. You must change your life. Cambridge: Polity Press, 2013.

Submetido em agosto de 2020 Aprovado em novembro de 2020

\section{Informações do autor}

Guy Barros Barcellos

Colégio João XXIII

E-mail: guy.barcellos@joaoxxiii.com

ORCID: 0000-0002-6950-6582

Link Lattes: http://lattes.cnpq.br/0723173364573238 